\title{
From theory to field experience with the non-destructive vibration testing of piles
}

\author{
A. G. DAVIS \& C. S. DUNN
}

\section{Dr Dunn}

The vibration test is more than an integrity test because it also gives a measurement of soil-pile interaction. Of particular importance is the measurement of pile head stiffness $E^{\prime}$, which is a dynamic measurement of the initial load settlement characteristic of the pile. It is useful to plot pile head stiffnesses of a population of piles of similar dimensions on a site where the geological profile is fairly uniform. Fig. 18 shows what was done on a site at Rossano de Calabro in southern Italy where 730 piles were tested. They varied in length from $14 \mathrm{~m}$ to $17 \mathrm{~m}$ and they had a diameter varying between $520 \mathrm{~mm}$ and $540 \mathrm{~mm}$. These were cast in situ end bearing piles passing through soft alluvium and founded in a conglomerate. The water/cement ratio of $0.33-0.40$ was rather lower than one would use in the UK and this, without doubt, accounted for some of the troubles that were experienced in installing these piles. The range of pile head stiffnesses was quite considerable. The average value was $0.60 \mathrm{MN} / \mathrm{mm}$ and the standard deviation was 0.23 .

72. It seems that for the first time one has a means of obtaining information enabling one to select piles intelligently and rationally for load testing. The problem until now has been that when a pile has been selected for load testing there has been no way of knowing whether or not that particular pile is an average pile, a good pile or a defective one. The load test results therefore could give no indication of the relative load carrying characteristics of the other piles. On the site in Italy it would have been possible to select one or two piles having a stiffness of $0.25 \mathrm{MN} / \mathrm{mm}$ knowing that $97 \%$ of the population of piles had a stiffness greater than this.

\section{Dr Davis}

Since the Paper was written, two modifications have been made to the equipment. First, it is no longer necessary to ensure that there are no extraneous vibrations on site, because an extra item in the recording circuit smooths out any spurious signals. Second, it is now possible to test raker piles using a special harness to position the vibrator in the line of the pile axis. Inclined piles up to a rate of one in four have similar values for pile stiffness as vertical piles on the same site.

74. One of the major restrictions of the method is the unlikelihood of receiving a reflected signal from the bottom of the pile when the pile length to diameter ratio is too great. A likely limiting upper ratio of 30 to 1 was suggested in the Paper. Subsequent testing in the Thames Estuary has shown that good results have been obtained for ratios up to 50 to 1 , where a very soft lateral soil has resulted in little damping, and the pile toe was founded in a stiff stratum. This is not the case for piles founded in stiffer lateral soils such as London Clay.

Paper published: Proc. Instn Civ. Engrs, Part 2, 1974, 57, Dec., 571-593. 


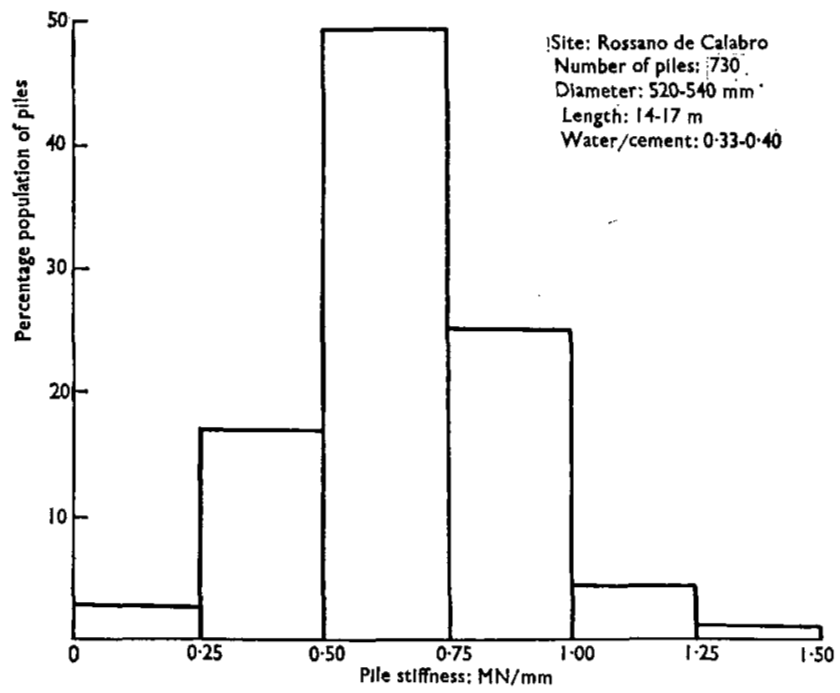

Fig. 18. Distribution of pile stiffnesses by vibration testing

75. The possibility of the vibration test giving information about pile-soil interaction as well as pile shaft integrity should be emphasized. Since the Paper was written, ten piles have been vibrated and load tested. Two of these test results are shown in Fig. 19, where TP1 was vibrated before load test and TP2 after load test. The first load increments were to $700 \mathrm{kN}$ so, given the lack of finesse, the resulting correlation between measured pile head stiffness $E^{\prime}$ and the equivalent load test stiffness can be considered reasonable. For smaller diameter piles, the correlation factor between $E^{\prime}$ and equivalent load test stiffness is of the order of $1 \cdot 4-1 \cdot 5$, and there is evidence to suggest that this is due to a strain rate effect.

\section{Mr G. E. Bratchell, Nachshen Crofts \& Leggatt}

My firm was appointed by Esso to investigate the causes of foundation failure of the two tanks at Fawley and to provide new foundations for them on adjacent sites. ${ }^{6}$ Reference 7 describes the lessons to be learned from that failure. Tests on 43 of the cast in situ piles at Fawley were carried out by CEBTP acting under instruction by $\mathrm{Mr}$ Ackroyd, and the resulting report was scrutinized by $\mathrm{Mr}$ Nachshen in conjunction with J. H. A. Crockett \& Associate and $\mathrm{Mr}$ Akroyd. The outcome leads me to agree with the statement in $\$ 3$ referring to the degree of mysticism, and I would warn prospective users not to let vibrations over-excite them.

77. My comments are limited to examining the usefulness and degree of reliability of the vibration method described, as revealed at Fawley. The purpose of this investigation was to establish whether or not the 43 piles tested, out of over 3000 installed, were of intact concrete for their full length. It is quite common with in situ piles for most of the concrete to be sound, but the load carrying capacity can be destroyed by gaps, cracks, necks and short zones of weak concrete, especially near the head of the pile. It is the positive detection of these which is so vital to a proper judgement of the acceptability of a pile. 


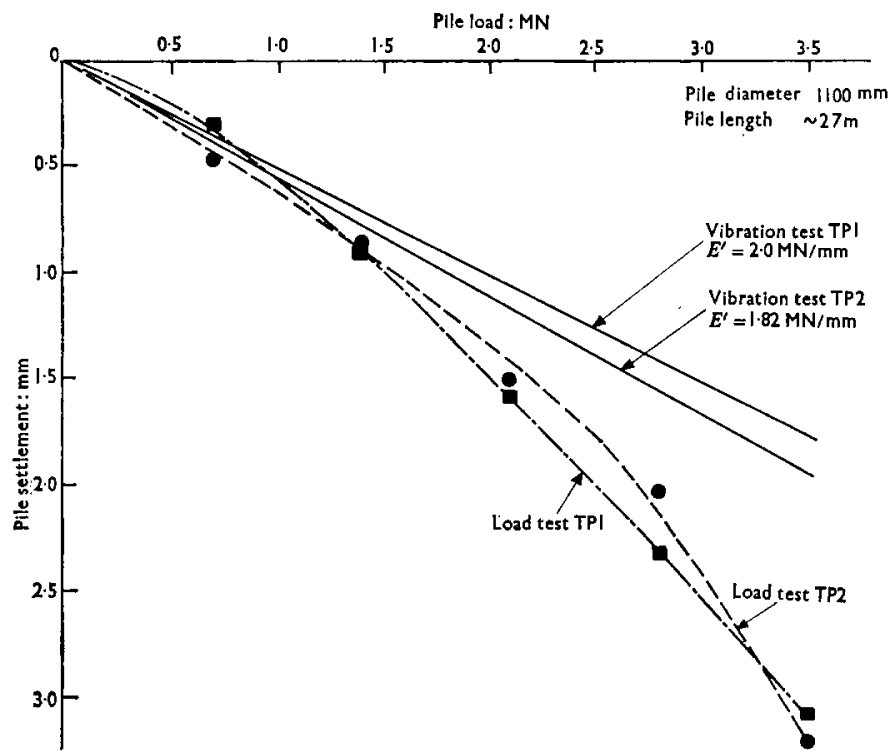

Test pile results: TPI

\begin{tabular}{c|c|c}
\hline Load, $\mathrm{kN}$ & Settlement, mm & Stiffness, MN/mm \\
\hline 700 & 0.30 & 2.33 \\
1400 & 0.90 & 1.56 \\
2100 & 1.58 & 1.33 \\
2800 & 2.31 & 1.22 \\
3500 & 3.06 & 1.15 \\
\hline
\end{tabular}

Test pile results: TP2 (reload curve)

\begin{tabular}{c|c|c}
\hline Load, $\mathrm{kN}$ & Settlement, $\mathrm{mm}$ & Stiffness, MN/mm \\
\cline { 2 - 3 } 700 & 0.47 & 1.49 \\
1400 & 0.86 & 1.63 \\
2100 & 1.50 & 1.40 \\
2800 & 2.02 & 1.37 \\
3500 & 3.20 & 1.04 \\
\hline
\end{tabular}

Fig. 19

78. The results of vibration tests are affected by variations in sectional area. At Fawley there were variations in sectional area ranging from a ratio of 2 to 1 on the same nominal pile size which would affect the response proportionately. In addition, there were considerable numbers of local variations observed in the same pile. It is also likely that the base restraint could be highly resistant to downward loads because the piles were driven to a set in gravel, but poorly resistant to uplift because they were only shallowly embedded in it. This presumably also affects the response.

79. It is possible that some of these piles were heaved and so one has to decide whether there is weak soil at the base of the pile or whether the pile has heaved from its bed.

80. With reference to the fourth sentence of $\S 58$, where defects near the tops of these 43 piles were observed in advance, these defective lengths were cut off before the piles were tested by vibration.

81. Paragraphs 59-61 and Table 4 give an inverted view of the purpose of the tests. It was not to arrive at the crushing strength of the concrete or the degree of stiffness of the alluvium, but to ascertain whether or not the piles were intact for their full length. The calculations which follow the vibration tests required an assumption of the concrete strength which, after considering the materials used, was estimated to be $15-20 \mathrm{MN} / \mathrm{m}^{2}$, which is reasonable. From this the velocity of wave propagation in the piles was calculated to be $3000-4000 \mathrm{~m} / \mathrm{s}$. Using this range, with the 
assumed pile sectional area, the concrete density and the measured wavelengths in the diagrams, calculations were made of a range of distances down from the tops of the piles. These calculated intact lengths, therefore, appear as a range of minimum length to maximum length, being not better than the ratio of 3 to 4 corresponding to the assumed concrete strengths.

82. Only eight piles met this criterion, but if the $20 \mathrm{MN} / \mathrm{m}^{2}$ value is increased to 21 , then eleven piles meet the criterion. A small change in the assumptions results in a large change in the number of acceptable piles.

83. Of the 32 piles found not to be intact, 17 were reported to be "quasiment coupé', i.e. discontinuous. The other 15 tests produced diagrams too confused to be interpreted and this is most disconcerting. It would be interesting to know what proportion of tests on other sites were not capable of interpretation. A test method for piles which gives less than two-thirds of interpretable results is not satisfactory.

84. Doubts are also raised by the statement in $\$ 62$ that a necking at $2.5 \mathrm{~m}$ from the head did not affect the vibration response. Furthermore, the test pile that had carried 160 tons was reported as discontinuous. Could this be explained?

85. A non-destructive testing method would be very welcome for piles and also for other concrete members. Those engaged in developing the method should be encouraged to improve their procedure and their method of obtaining data. Calibration against other methods should be developed, e.g. comparison with concrete cores. The results of vibration testing should be treated as only part of the information to be considered by an engineer experienced in piled foundations, in deciding whether or not a pile is acceptable. Equally important is the dispersal of the mysticism mentioned. As with other testing, only completely unbiased presentation of results will inspire confidence.

Mr J. F. Levy, Deputy Structural Engineer, Architect's Department, Greater London Council

I am often associated with bad piles and integrity testing, but from the earliest days of my discussions with CEBTP on vibration testing I came to the conclusion that one of the most important potential uses of the method was for testing all the piles on a site to decide which of the working piles, as distinct from the preliminary piles, should be load tested.

87. However, I have been unaware that there were any piles which had both vibration tests and load tests carried out on them.

88. Could the Authors explain Fig. 19? I did not get the impression that there was a direct relationship between the vibration results and a deduced load which a pile could carry. Is Fig. 19 intended to show that there is the same relationship between the two vibration results as there was between the two load results?

Mr D. B. O'Neill, Crockett \& Associate

I think that any system which uses vibration beneficially is praiseworthy. Some years ago my firm was asked to conduct vibration tests on some large diameter piles which were suspected of gravel inclusions within their length. The piles had been concreted to ground level and when the basement was excavated some piles literally fell over. Mounting a research project on a busy building site is not easy and we had to work at night and at weekends to obtain noise free conditions.

90. We tried several methods, the reflection time of a shock wave from a discontinuity, the resonant frequency of end to end vibration of the fractured pile length (i.e. a simplification of the Authors' method) and the reflection time of a short burst of waves of a discrete frequency enabling all other frequencies to be filtered out. The latter appeared to be promising. Unfortunately time and money were limited and the system was not finalized.

91. The Authors' method of pile testing shows real promise, although I shall be 


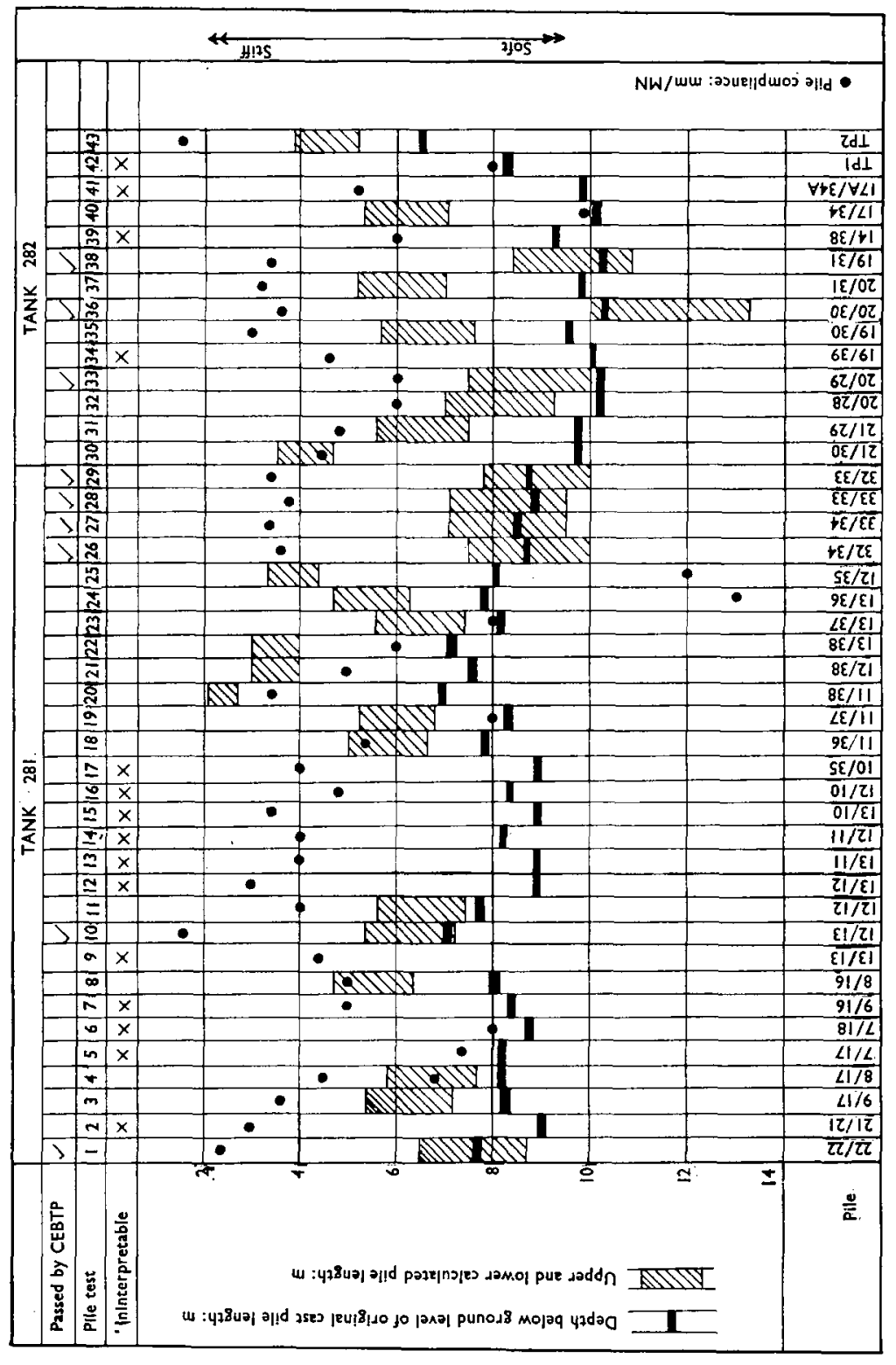

온 
more convinced when there is greater correlation of the theory with practice. There often appear to be uninterpretable variations between site records and the theoretical curves. Perhaps test piles could be buried horizontally in a trench thus enabling controlled defects to be introduced and examined. Gravity effects can be safely ignored.

92. I had to criticize the Authors' Fawley results professionally in Court. Fig. 20 shows the results of the test carried out by CEBTP on 43 piles at Fawley. The site recorded length of each pile is plotted together with a shaded zone representing the upper and lower length limits (determined by the tester's estimate of the limiting propagation velocity in the concrete) within which the test showed a discontinuity. Also plotted and shown by dots is the pile compliance, i.e. the softness, or the inverse of stiffness. In 15 cases the test results were too complicated to be interpretable, although in every case the initial slope of the graph was clear enough to yield a compliance value.

93. The assumption that the slope of the graph is straight between the origin and $20 \mathrm{~Hz}$, where the frequency test begins is, to my mind, incorrect because it ignores the possibility of resonance of the pile as a rigid body in the elastic soil at frequencies in this range. Such a resonance would indicate an incorrectly high compliance. Has any investigation into the low frequency response of piles been conducted?

94. The Fawley report suggested that the average piles exhibited unacceptably low stiffnesses. The average was $5 \mathrm{~mm} / \mathrm{MN}$. This sort of figure compares not unfavourably with that commonly accepted statistically on such piles.

95. There are some anomalies on the graphs. Test piles 21 and 25 have discontinuities at about the same level, but have compliances of 5 and $12 \mathrm{~mm} / \mathrm{MN}$ respectively. Similar anomalies are to be found between piles 19 and 24 , and 37 and 40 . Pile 35, which has a discontinuity in its length, is twice as stiff as pile 33 , which was accepted as sound throughout its length. Such an increase is surely unlikely to be due solely to bulbing at a high level. I feel that, in the absence of a better explanation, the probability is that the resonant behaviour could well be the explanation for these anomalies.

96. This test method, with refinement, will provide a most valuable tool.

\section{Mr S. A. Robertson, Testconsult Ltd}

Testconsult Ltd is the UK subsidiary of CEBTP.

98. I should like to clarify the point regarding the dispersal of the results based on the different assumptions which have to be made to fit into the graph-in particular the velocity assumptions between $3000 \mathrm{~m} / \mathrm{s}$ and $4000 \mathrm{~m} / \mathrm{s}$. These values relate to very poor and very good concrete respectively, and vary according to the density of the aggregates and so on. It is hoped that in time it will be possible to establish more accurately the assumptions that should be used on concretes in the UK.

99. These methods were developed in France. It would have been possible to obtain more accurate results if some of the cores taken from those piles at Fawley had been tested in the laboratory to establish a strength/velocity correlation and the information then used in the calculations.

\section{Mr E. L. Barron, Eastern Gas}

I have been trying to draw some parallels between the situation on non-destructive testing for piling systems and the girth welds of high pressure gas pipelines in the UK. Originally $10 \%$ radiography was specified, but $100 \%$ was later used in order to reduce to a minimum the risk of pipeline failure arising from weld defects. Similarly testing one or two piles with a load will leave a high risk of defective piles in the remainder. $X$ radiography is now used because it shows some significant defects more clearly than gamma. Even with $\mathrm{X}$ radiography some serious defects can still be missed, so it is necessary to rely on quality control in the form of welding procedures and adequate supervision during production welding. 
101. The pile vibration testing techniques are similar to ultrasonic methods for the testing of welds which are used as a supplement to $\mathrm{X}$ radiography. Although the vibration technique is invaluable, it needs to be supplemented by other non-destructive testing techniques. All this testing is compliance testing and is no substitute for control testing during construction. In Japan a simple ultrasonic device has been developed which enables the welder to check his work as he goes along.

102. The analogy can also be applied to trends. For low pressure pipelines (less than 7 bar), no radiography is now required and partial penetration welds are permitted. For lightly loaded piles, or where large settlements or the failure of some individual piles can be tolerated, visual inspection during construction should suffice. Having decided the normal standard of acceptance, attention is now turning to the avoidance of costly repairs. Standards are being defined for acceptance of defects below the normal standard, possibly with reduced payment, with remedial measures to bring the standard back to normal. With piles, normal standards of acceptance will have to be agreed, and the engineer will have to decide if piles not meeting this standard can be accepted or have to be repaired or replaced.

103. The need for both control and compliance testing, and the variation of risk to both contractor and customer with the number of tests, have been explained in reference 8 . The Japanese ultrasonic test equjpment has been described in reference 9. This should be useful for control testing but it will not supplant the established methods for compliance testing. It has been used on an experimental basis in Japanese shipyards and the customer's superintending engineer has confirmed its efficacy in reducing defects revealed by compliance testing.

\section{Mr W. P. Came, Frankipile}

Experimental testing was recently carried out by CEBTP on Frankipiles at a site using this equipment. It would be interesting to know if these tests have been interpreted and how the Frankipile compares with other types of pile such as the step taper pile and a pile constructed under bentonite as tested on an adjacent site.

105. A method of integrity testing whereby a number of piles can be sampled prior to a choice being made for load testing is to be recommended. However, it is doubtful if it is possible to determine whether or not a pile is capable of carrying its load and to design piles on such a method.

106. It would be interesting to know the approximate costs of testing and whether the method could be made simple enough so that the tests could be carried out and interpreted by the contractor's site staff. This would allow any suspect pile to be dealt with immediately while the pile driving rig was still in the area rather than necessitating waiting for a specialist testing service which might not carry out tests until some weeks later.

\section{Mr A. C. Meigh, Soil Mechanics Ltd}

The Authors have referred to the oil tank foundations at Fawley as one of their case histories and have made a selective reference to 11 piles out of 43 tested. They state that the test results confirm the design length of the 11 piles, but do not point out that the results of the other tests did not permit sensible interpretation. It is known from reference 5 that the events at Fawley were the subject of litigation and I think it is worth recalling that the tests were put forward by the Defendants' experts in that litigation to show that the piles tested were sound below the level to which they had been examined in excavations made below the slab. However, the expert witnesses for the Plaintiffs, using the same data, concluded that the data was so uncertain that any deductions from it must be speculative, if not misleading, and that if the tests indicated anything it was directly opposed to the views of the Defendants. It is unfortunate in relation to this problem that the case was discontinued before a judgement was made, but $I$ doubt whether the test results could have helped in a judgement 
in view of the uncertainties and the strongly held conflicting views of the expert witnesses.

108. Two general points arise from this. First, if the Authors have been so selective in their presentation of the Fawley results, and I believe misleading in their claim for the value of those results, what can one think about their objectivity in relation to the other sites they have quoted? Second, it would appear to me that methods of testing the quality of works construction should be unambiguous if they are to reduce rather than increase the area of possible dispute between contractor and employer. The method put forward by the Authors does not meet this criterion.

\section{Dr Davis and Dr Dunn}

To answer Mr Levy and Mr Came about the possible relationship between vibration testing and static load testing, reference can be made to Fig. 19. In no way can the vibration test predict the ultimate load carrying capacity of a pile; the pile head stiffness $E^{\prime}$ has been plotted in Fig. 19 as a load/settlement ratio for convenience of comparison with the load test results at low loads.

110. Comparisons of the performance of the vibration test on different proprietary pile types and differing construction methods have shown that the method is at its best when testing the geometrical shape for which it was developed, i.e. the continuous right cylinder. Departures from this shape such as intended joints, expanded bases and step tapers reduce the degree of information obtainable. In the case of Frankipiles, excellent results were obtained to the top of the expanded base, but the depth to the toe of the base could not be measured. However, the measured pile stiffnesses $E^{\prime}$ were very close to the measured values of $E^{\prime}{ }_{\max }$; this showed that most of the load at the head of the pile was being transferred to a good anchorage at the pile toe.

111. The approximate cost of testing is $£ 40-£ 45$ per pile (1975 prices), including transportation. It is not likely that the method will be simplified to the extent that contractor's staff on site could interpret the response curves, unless the contractors in question trained an engineer specifically for this purpose.

112. Mr O'Neill makes the constructive suggestion that some research might be carried out on horizontal piles with purposely included faults, for ease of examination. However, the disadvantages of this possibly outweigh the advantages because placing a pile horizontally ignores the fact that one is interested in pile-soil interaction, which is dependent on the effective stress and shaft friction. Effective stress is a function of soil stress history, overburden pressure and water table position, and the development of shaft friction is related to the horizontal effective stress developed around the pile, which changes with depth.

113. For pile resonance to occur at frequencies lower than $20 \mathrm{~Hz}$, Fig. 4 shows that this is possible with a very long thin rod with virtually no lateral damping, or a very heavy mass founded almost at ground surface. Novak ${ }^{10}$ has shown that an increase in both stiffness and damping due to the lateral soil as embedment increases has the effect of reducing the amplitude of the returning signal and increasing the first resonant frequency, so for most piles which are not badly broken near their head or are not founded in what is virtually soup, there is some reason to believe that the first resonant frequency is greater than $20 \mathrm{~Hz}$.

114. The average pile stiffness for the eleven sound piles at Fawley to which Table 4 refers was $0.31 \mathrm{MN} / \mathrm{mm}$. These piles had a nominal pile shaft cross-sectional area of $0.145 \mathrm{~m}^{2}$, and from Fig. 17 the pile head stiffness would be expected to be of the order of $0.5 \mathrm{MN} / \mathrm{mm}$, as had been found in several cases in Europe for piles of this dimension.

115. It is not necessarily an anomaly that produces two very different stiffness results from two piles with discontinuities or faults at the same level. The nature of the discontinuity affects the value of $E^{\prime}$ measured at low frequencies; if the fault is minor (e.g. a small crack), the part of the pile below the fault can affect the stiffness 
value $E^{\prime}$, whereas if the fault is a complete void or badly broken concrete over the whole pile section, this will not be the case.

116. Mr Bratchell is correct in saying that the Client's reason for asking for the vibration tests at Fawley was to establish the continuity or otherwise of the piles. However, we used the results which appeared incidentally from the tests to show one of the possibilities that the method has to offer, i.e. the study of pile-soil interaction.

117. Mr Bratchell is not quite correct in saying that calculations of length down to the reflected signal require assumptions about the concrete strength. In fact they require a knowledge of $v_{\mathrm{c}}$, which is not uniquely related to strength. A reasonably accurate value of $v_{\mathrm{c}}$ can usually be calculated from equation (3) taking $A_{\mathrm{c}}$ as the nominal cross-section of the pile. The length of the pile is calculated for convenience using upper and lower bound values of $v_{\mathrm{c}}$ corresponding to poor concrete $(3000 \mathrm{~m} / \mathrm{s})$ and good concrete $(4000 \mathrm{~m} / \mathrm{s})$.

118. Only four of the 43 piles tested at Fawley produced results which were uninterpretable. Apart from the eleven piles discussed in $\$ \$ 57-62$, each of the remaining 28 piles showed a reflexion from a point well above the pile toe. The nature of the features causing these reflexions when they occurred below exploratory heading levels was never investigated.

119. Mr Meigh questions the objectivity of our interpretation of results from other sites by referring to our selectivity of the results from Fawley. Whatever the Client who ordered the testing at Fawley wished to prove, we have been selective with the results from that site for one purpose only: to demonstrate the possibilities in the vibration testing method for the study of pile-soil interaction - a subject about which little is known. If $\mathrm{Mr}$ Meigh is questioning the ability of the vibration method to play an independent role in contractual matters and control testing, then he must refer to those clients in the UK who have used vibration testing on no fewer than ten occasions since October 1974.

120. The vibration test is an indirect non-destructive test method, and like all such methods can only be used in conjunction with other information available from other methods. As a parallel, geophysical exploration using seismic techniques has been successfully applied to certain geotechnical problems only when an adequate knowledge of the soil profile has been available from good borehole records and geological interpretation. Similarly, the vibration method requires as complete a knowledge as is possible of the soil conditions, pile type and method of construction, problems during construction and any ancillary information such as the volume of concrete poured per pile. In no way can the results be fully interpreted without this background information.

\section{References}

6. Leggatt A. J. and Bratchell G. E. Submerged foundations for 100000 ton oil tanks. Proc. Instn Civ. Engrs, Part 1, 1973, 54, May, 291-305.

7. Bratchell G. E. and Megit J. S. C. Abandonment of 100000 ton piled tank bases at Fawley: matters investigated and lessons learned. Private communication, 1975.

8. Concrete Society. The philosophy of testing. Concrete, 1971, 5, May, 148.

9. In Quality control and non-destructive testing in welding. Welding Institute, Cambridge, 1975.

10. NoyaK M. Discussion on Response of embedded footings to vertical vibrations. J. Geotech. Engng Am. Soc. Civ. Engrs, 1974, 100, GT5, May, 562. 